\title{
Philosophy of the Construction Elements of Fashion
}

\author{
Elsayed Ahmed Elnashar* \\ Full-Professor of Textiles \& Apparel, Kafrelsheikh University, Egypt
}

*Corresponding author: Elsayed Ahmed Elnashar, Full-Professor of Textiles \& Apparel, Faculty of Specific Education, Kafrelsheikh University, Egypt, Email: Smartex@kfs.edu.eg

submission: 監 November 10, 2018; Published: 㓝 November 13, 2018

\section{Introduction}

Fashion philosophy is not in essence but a network of intellectual relations and mental appeals, which calls on each researcher to work his mind in the study of the issues presented to him without waiting for what others have said, but not limited to the general public. Fashion designing is the creative field in which trendy and appealing apparels or accessories are designed. Aesthetics experience and Fashion technology covers the manufacturing process and involves a wide usage of technology in the production of apparels. Designing is a creative process. Design can be seen to be a creative, magical, intuitive, and elusive process. It is a process for creating solutions with respect to a given problem. In fact, design is form of problem-solving, or a way of looking at a problem whose primary goal is to solve a complicated problem and to create or explore innovative options. Philosophy of the design process transforms ideas into reality, based on designers' conceptual ideas with respect to practical solutions.

Taking into account the reduction without prejudice and the obligation of originality without prolongation. Fashion is a work of art which means "sense of unity" as a gem of a constructive activity or constructive constructor Various fashion designers and patternmakers have used slightly different approaches in achieving Aesthetics experience the final design of a sample garment, and apparel and fashion designers tend to use a range of mental processes when dealing with designing and creating innovative works. Philosophy to a greater extent, numerous fashion designers around the world have adopted a conceptual approach in sharing their story around the world as Color and symbolism in the clothing of the Folk Arts Division of Marsa Matruh city in Egypt, To Benefit from the Development of the Egyptian Heritage in the Trends of Modern Fashion. We decide that it is not an Aesthetics study to put us in the fashion of artists or creative but put us glare to the face of works of art and creative assets will not be able to prepare fashion just a personal reflection or self-reflection by the artist, but we find ourselves critical of the recognition that fashion is Total necessities imposed on the artist.

Philosophy it takes the essential elements of great effort and plentiful experience to become expert in a field; thousands of hours of deliberate practices may be required to create a first significant work. Theoretically, it takes an average time of a decade for a novice to master the abundant skills and levels of technical expertise required to become a professional capable of producing extraordinary products, although this time may vary. For example, 20 years (science 1995) of practice and experiences of Aesthetics experience May be required to become a creative musical composer; several years of preparation and practice might be typical for a painter, and a poet. There is limited research regarding the average years of experience to become an expert fashion designer. Philosophy As a standard and support to the core of his Aesthetics experience in the fashion dress and fashion and calculated to look at the subject of art in order to verify that it must come on a static impact of the path of human activity in the movement of production.

Fashion is that effective realism that all other works of art exist. And that at the heart of every work of art is the ultimate proof of the rush of idealism. Fashion is something between the spiritual powers possessed by man. Those creative forces that can build a whole world? philosophy Is not the fashion is that strange magician, which goes to the nukes a fatal blow when you push the boiling existence with its non-existent creatures (such as the symphonies, musicals, poetic epics) and visual products that occupy their place in the world of reality, and in a world of the human creature and that these creatures created by artists and which fascinate people at all times and places are philosophy fantastic creatures combining the word fashion, but in fact differentiated, if fashion is called object esthetic, our attention is a subject of attention and hope. Some of the themes of fashion trends such as the return of nature (such as sunsets or flowers opening can become aesthetic themes, but fashion includes only the creations of human creation, But it is specifically this important role played by the senses in the circle of aesthetic experience, as well as in the fashion of dependence on the imagination, the various stimuli must be able to represent the senses or senses so that it can provoke our responses to the resignation or imagination or emotion and not from Fashion, however, has to evoke sensation and imagination to the same degree, but one must touch one another. But there is virtually no sensory perception without arousing memories in the mental images stored in my computer database or the human memory of the artist.

And we conclude by saying that every attempt to define fashion must ultimately put us face to face with a work of art as the aesthetic 
subject that we first and foremost sense, so we must stand on the nature of structural elements of the structure of fashion, Fashion:

\section{Elements of the structure of fashion}

1) Material and shape (raw-color-shape(: These include: Textile filaments yarns, colors, fabrics, models, patrons, fashion, accessories, fittings.

2) Subject: Fashion trends such as back to nature, nostalgia for the past, memories of the past Scandinavian, dark asphalt colors, military uniform, Canadian woods, precision and elegance.

3) Expression: Is a way of fashion expression on fashions in fashion trends using different types of filaments, threads, fabrics, colors, materials, accessories and equipment that achieve the direction required according to the vision of the designer and the community in which he lives.

4) Signification: What are the values that we will get through fashion in general and for fabrics and fashion special bouquet which, for example:

a) Economic values to open new markets for the product and a huge financial return.

b) Social values - customs - traditions - ethics,

c) Technical values

d) Religious values

e) Political values

5) Philosophical values

Philosophy a fashion designer must possess aesthetics experience of a good knowledge of color, textile detail and style. The key word which describes fashion designing is original. philosophy All the products of fashion designing must be original creations. A fashion designer first creates sketches of the designs and then select fabrics and patters. After the selection, he or she provides the necessary instructions on the way these products will be designed.

Philosophy fashion designing and fashion technology are generally considered to be closely related and therefore many times, the terms are collectively used as Fashion design and Technology. However, there is a difference between them. Aesthetics experience and Fashion designing deals with the designing aspect of this industry, in which fashion designer focuses on designing innovative clothes and accessories. On the other hand, fashion technology is more about use of technology for the production of the fabrics. It is the technical aspect of the fashion domain the types of designs.

\section{Types of designs}

Sensory design: It is sensed through the senses of vision, or hearing, and can be sensed through the texture or taste and classify the sensory design to: (Visual - audio - touch - taste).

Behavioral design: Is affecting the production and consumption of clothing, there are many factors that affect the behavioral design of the designer, namely the rules of banks and policies of openness and advertising, market system and family budget these factors affect the behavior of the designer.

Functional design: Is primarily related to the design function "Here we mean fashion design", and the purpose for which it was designed, namely the functional aspect of the costume, when developing the idea, puts the designer in mind the function of the thing to be designed.

Structural design: For the design work in textiles in general and textiles and clothing in particular, the choice of suitable and appropriate materials should be noted.

Decorative design: is rhythm throw the design on an object is basically additional decorations (make up) are applied to produce beauty. Decoration itself plays as a medium to enhance, beautify or to make a graceful works of art.

\section{Benefits of Publishing with us}

- High-level peer review and editorial services

- Freely accessible online immediately upon publication

- Authors retain the copyright to their work

- Licensing it under a Creative Commons license

- Visibility through different online platforms 